\title{
傾斜板内插型気固接触装置の流動特性
}

\author{
永田 啓 吾*, 村 瀬 和 典*, 山口 浩 司* \\ 金 井 憲 志*, 中 村 正 秋*, 外 山茂 樹*
}

\section{The Flow Properties of a Gas-solid Contactor with Inclined Baffle Plates}

by

\author{
Keigo NAGATA ${ }^{\dagger}$, Kazuo MURASE $^{\dagger}$, Hiroshi YAMAGUCHI $^{\dagger}$ \\ ${\text { Kenji } \mathrm{KANAI}^{\dagger} \text {, Masaaki NAKAMURA }}^{\dagger}$ and Shigeki TOYAMA ${ }^{\dagger}$
}

\begin{abstract}
The behavior of particles in a gas-solid contactor with inclined baffle plates to form a zig-zag path has been experimentally studied. In this contactor, solid particles trickle down over the baffles and are spouted into the opening between the wall and the plate edge by upflowing gas. The pitch, open spacing fraction and inclination of the baffles are chosen as parameters of the experimental condition. The loading and flooding points are observed at critical gas velocities in using this apparatus. A definite increase in the solid holdup and residence time of solid particles is also observed at the loading point, and particles choked the column at the flooding point. To investigate these properties thoroughly, trajectories of a single partcle are calculated in a two-dimensional field of the gas velocity measured with a hot wire anemometer.
\end{abstract}
Key Words : Distribution of Gas Velocity, Gas-solid Contactor, Inclined Baffle Plates, Holdup of Solid Particles, Particle Trajectories, Pressure Drop

\section{1. 緒言}

気体と固体粒子の接触装置は, 粒子の移動形態から 固定層, 移動層, 流動層, 輸送 (気流)層などに分類さ れ, 粒子の加熱, 冷却, 乾燥, 化学反応に用いられて いる。気流の圧力損失を比較的小さく抑え, 湿潤粒子 の解砕・分散効果も期待されるバッフル内挿型気固向 流型接触状置も使用されている。バッフルとしては充 填物をランダムに詰めたもの ${ }^{1,2)}$, 角材を一層ごとに直 交配列したもの ${ }^{3)}$, 前報の山形鋼を状せて平行に配列 したもの4)などがある。

1994年 7月 20日受付

* 名古屋大学工学部分子化学工学科

( (464-01 名古屋市千種区不老町) TEL. 052-789-3618

$\dagger$ Dept. of Chem. Eng., Nagoya Univ.

(Furo-cho, Chikusa-ku, Nagoya 464-01)
山形鋼を伏せて平行に配列した場合, 気流は山形鋼 の凹部に衝突し, 粉粒体を巻き込んだ循環流を形成し 粒子滞留量ならびに気固接触面積を增加させる効果が 認められた の量が比較的少ない場合において, 山形鋼による循環 流の影響をより明らかにするため, バッフルのサイズ を大きくし, 流路に傾斜板を交互に配列した傾斜板内 挿型気固接触装置を試作した。これにより, ジグザグ 流路における気流の速度分布を測定し, 単一粒子の運 動軌跡を数值解析した。一方, 粒子滞留量ならびに圧 力損失に及ぼす内挿板の形状の影響を調べた。

\section{2. 実験装置および方法}

Fig. 1は実験装置のフローシートである。ブロワ一 で吸引された空気は流量計を通った後, 装置下部から 


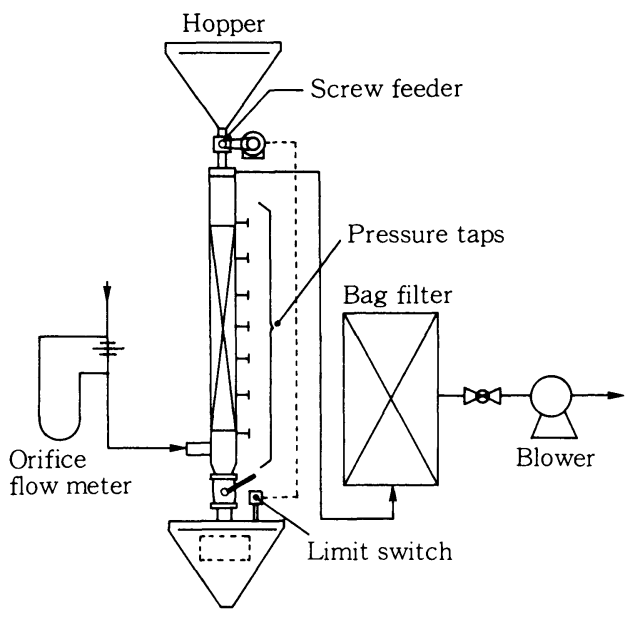

Fig. 1 Schematic view of experimental apparatus

供給され，上方に向かって流れる。固体粒子は装置上 部からスクリューフィーダーにより一定流量で供給さ れ，下方に向かって流れる。定常状態になった後，装 置底部に取り付けたボールバルブを急閉し, 粒子フィ 一ダーおよびブロワーを同時に停止し, 装置内に滞留 する粒子量を测定した。

装置本体の寸法は幅 $X=170 \mathrm{~mm}$, 厚さ $50 \mathrm{~mm}$, 高さ $1500 \mathrm{~mm}$, 前面と後面は内部観察用に透明アクリル板 で作られている。装置内部には，Fig. 2に示すように 傾斜板が垂直距離 $Y$ 毎に交互に配置されている。傾斜 板を水平面と角 $\theta=40^{\circ}$ あるいは $45^{\circ}$ と, 粒子の安息角 以上にとった。傾斜板の水平方向長さを $S$ とし, 開口 比を $E=1-S / X$ で求めた。

粒子を流さないときのガス速度分布をI 型プローブ

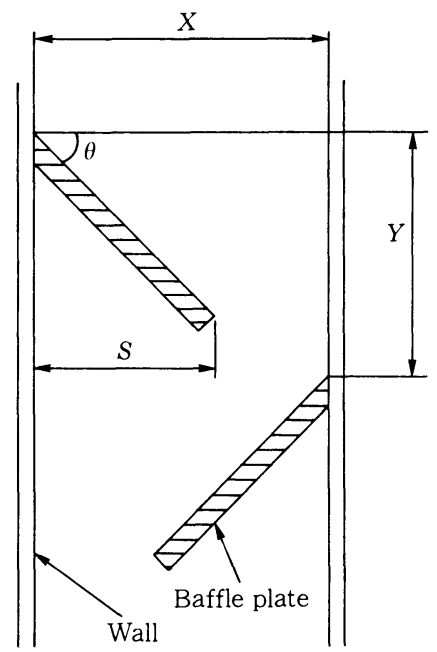

Fig. 2 Details of inclined baffle plates
を使用する定温度熱線流速計で測定するために，装置 前面のアクリル板にプローブ挿入用の穴を $10 \mathrm{~mm}$ 間隔 で垂直方向に31点, 水平方向に17点設けた。

粒子は, シリカサンド $\left(50 \%\right.$ 径 $d_{\mathrm{p}}=0.25 \mathrm{~mm}$, 密度 $\rho_{\mathrm{p}}$ $=2650 \mathrm{~kg} / \mathrm{m}^{3}$, 終末速度 $v_{\mathrm{t}}=1.44 \mathrm{~m} / \mathrm{s}$ )を用いた。

\section{3. 粒子滞留率と圧力損失}

前 報 ${ }^{4)}$ で山形鋼を内挿した場合と同様, 締め切り法 による気固二相向流接触時の粒子滞留率 $f_{\mathrm{p}}$ と, 固体粒 子が存在することによる圧力損失の寄与分 $\Delta P_{\mathrm{s}}(=$ $\left.\Delta P-\Delta P_{0}\right)$ をFigs. 3 および 4 に示す。Fig. 3におい て粒子滞留率 $f_{\mathrm{p}}$ は低ガス流速域でほとんど一定であ り, ある流速以上で増加が始まり, 高流速域で急激に 増大している。一方, Fig. 4の圧力損失 $\Delta P_{\mathrm{s}} / L$ とガス 流速 $u$ との関係も同様の関係にある。ただしFig. 4に おいて, 低ガス流速域で, $\Delta P_{\mathrm{s}} / L$ の值が粒子供給量 $F に$ にかわらず, 非常に小さな值をとるのは, 低ガス 流速域では, ガスの影響が少なく, 粒子滞留量(ホー ルドアップ)が粒子供給量 $F$ の值に関係なく一定とな るためである。このように, 装置内に供給される粒子 の量が比較的少ない場合, 前報 ${ }^{4)}$ で山形鋼を内挿した 場合に観察された場合と同様の結果を示し, $f_{\mathrm{p}}$ の増加

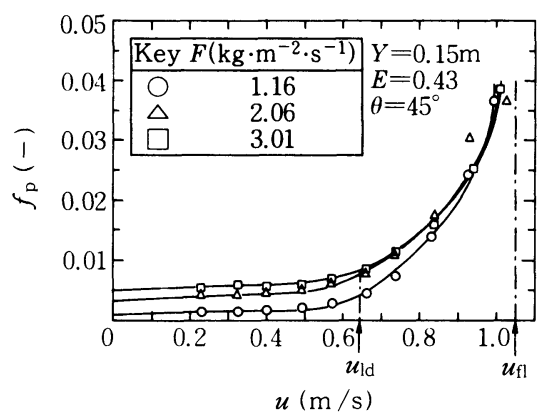

Fig. 3 The effect of the solid feed rate on the volume fraction of solid particles

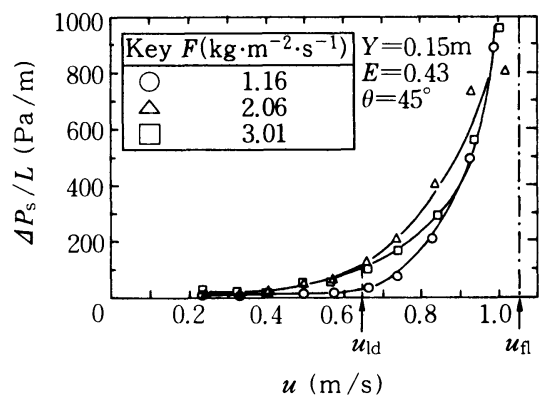

Fig. 4 The effect of the solid feed rate on the pressure drop due to solid particles 


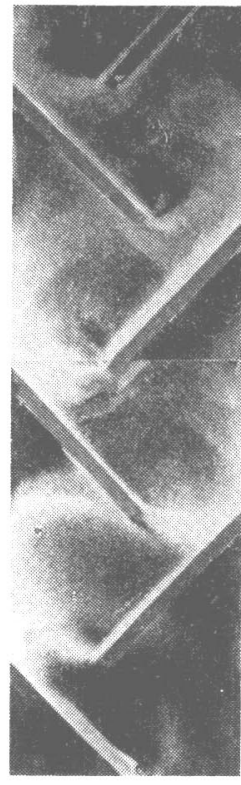

at the loading point

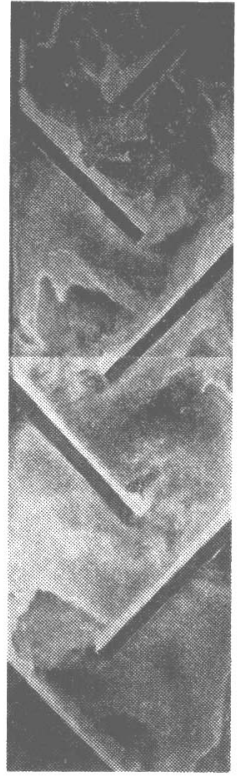

at the flooding point
Fig. 5 Flow behaviour of solid particles in the gassolid contactor

が始まるガス流速をローディング(loading)開始速度 $u_{\mathrm{ld}}$, 圧力損失が大きく, 操作不能となるガス流速をフ ラッディング(flooding) 速度 $u_{\mathrm{fl}}$ と呼ぶ。Fig. 5は, ロ 一ディング開始直後およびフラッディング開始直前の 流動状態を示す。ローディング状態では, 傾斜板の先 端で粒子がガス流によって上方に運ばれ，循環流を形 成している様子が観察される。フラッディング状態に 近づくにつれ，粒子は激しく乱れた循環運動を行い, 粒子滞留量が急激に増加する。

Fig. 3は粒子供給量 $F$ が $f_{\mathrm{p}} に$ 与える影響を調べたも のであるが，ここで用いたFの範囲では, 他の条件が 一定の時, $u_{\mathrm{ld}} お よ ひ ゙ u_{\mathrm{fl}}$ の值はほぼ同じであった。

Fig. 6は，傾斜板の設置間隔Yの影響を見たもので

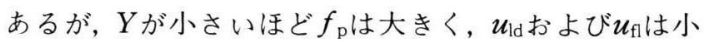
さくなる傾向にあった。

傾斜板の開口比 $E$ と $f_{\mathrm{p}}$ の関係を Fig. 7 に示す。 $E$ が 小さいほど $u_{\mathrm{d}}$ および $u_{\mathrm{fl}}$ は小さくなるのは, 開口部を流 れる平均ガ ス速度が $u_{0}=u / E$ と大きくなるためであり, 結果の一例をTable 1 にまとめた。これより $u_{0}$ の值が 粒子の終末速度 $\left(v_{\mathrm{t}}=1.44 \mathrm{~m} / \mathrm{s}\right)$ 以上になると，ローデ イングが開始されることが分かる。また，これらの結 果は, 前報 ${ }^{4)}$ に用いた山形鋼の間隙を小さくすれば, 少ないガス流速でも, 粒子滞留量の増加効果が期待で きることを示すものである。

傾斜板の角度 $\theta$ を $40^{\circ}$ おび $45^{\circ}$ と変えたが， $f_{\mathrm{p}}$ およ

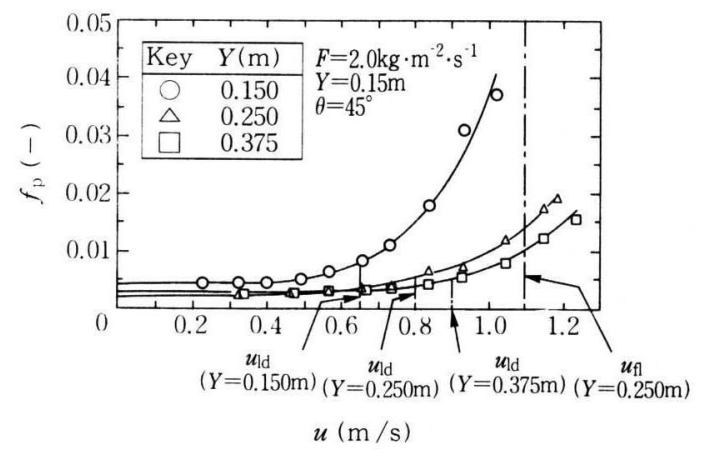

Fig. 6 The effect of the pitch of baffles on the volume fraction of solid particles

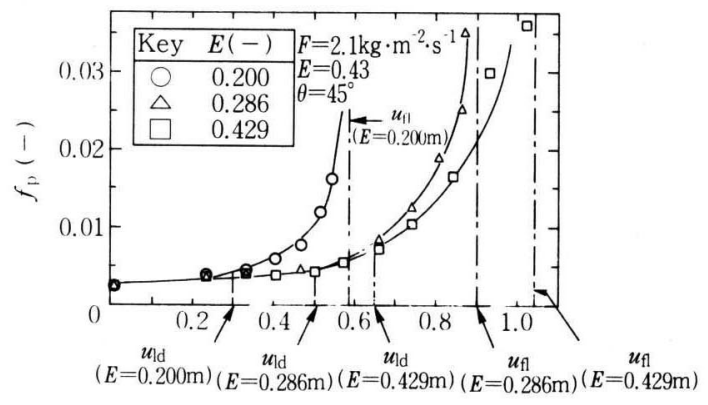

$$
u(\mathrm{~m} / \mathrm{s})
$$

Fig. 7 The effect of the open spacing fraction on the volume fraction of solid particles

Table 1 Experimental results of the loading and flooding velocities at $F=1.2 \mathrm{~kg} \cdot \mathrm{m}^{-2} \cdot \mathrm{s}^{-1}$ and $\theta=45^{\circ}$

\begin{tabular}{cccccc}
\hline $\begin{array}{c}Y \\
(\mathrm{~m})\end{array}$ & $\begin{array}{c}E \\
(-)\end{array}$ & $\begin{array}{c}\boldsymbol{u}_{\mathrm{ld}} \\
(\mathrm{m} / \mathrm{s})\end{array}$ & $\begin{array}{c}\boldsymbol{u}_{\mathrm{ld}} / \boldsymbol{E} \\
(\mathrm{m} / \mathrm{s})\end{array}$ & $\begin{array}{c}\boldsymbol{u}_{\mathrm{fl}} \\
(\mathrm{m} / \mathrm{s})\end{array}$ & $\begin{array}{c}\boldsymbol{u}_{\mathrm{f} 1} / E \\
(\mathrm{~m} / \mathrm{s})\end{array}$ \\
\hline 0.100 & 0.429 & 0.70 & 1.63 & 1.30 & 3.03 \\
0.150 & 0.200 & 0.30 & 1.50 & 0.60 & 3.00 \\
0.150 & 0.286 & 0.50 & 1.75 & 0.95 & 3.32 \\
0.150 & 0.429 & 0.65 & 1.52 & 1.05 & 2.45 \\
0.250 & 0.429 & 0.65 & 1.52 & 1.20 & 2.80 \\
0.375 & 0.429 & 0.65 & 1.52 & 1.30 & 3.03 \\
\hline
\end{tabular}

び $\Delta P_{\mathrm{s}} / L の$ 結果に差異はなかった。これは, いずれ の場合も粒子の安息角以上の值であったためと考えら れる。

気固接触効率を高めるには, ガス空塔流速を $u_{\mathrm{d} 1}<u$ $<u_{\mathrm{fl}}$, すなわちローディング状態の範囲で操作すべき であるので，この範囲の圧力損失 $\Delta P_{\mathrm{s}} / L$ を片対数グ ラフで整理し直してみると, Figs. 8および 9 となり，ガ 又空塔速度 $u$ に対しほぼ直線関係にあることが分かる。

$$
\log \frac{\Delta P_{s}}{L}=a u+b
$$




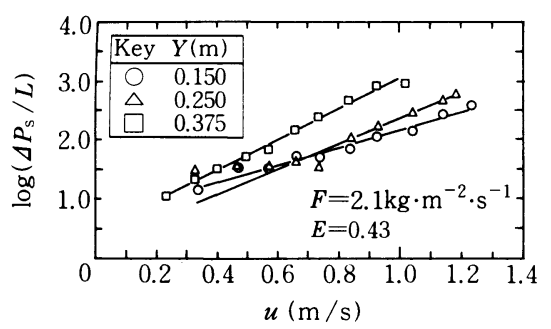

Fig. 8 The effect of the pitch of baffles on the pressure drop due to solid particles

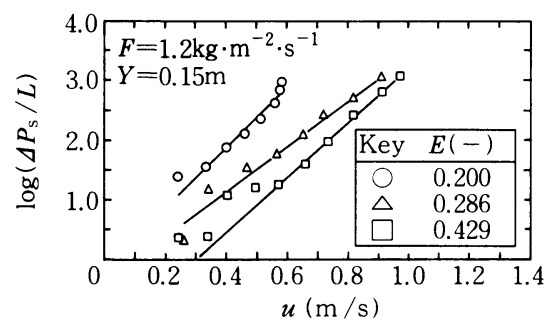

Fig. 9 The effect of the open spacing fraction on the pressure drop due to solid particles

Table 2 Coefficients $a$ and $b$ in Eq. (1) for the pressure drop due to solid particle flow $\left(\theta=45^{\circ}\right)$

\begin{tabular}{ccccr}
\hline $\begin{array}{c}Y \\
(\mathrm{~m})\end{array}$ & $\begin{array}{c}E \\
(-)\end{array}$ & $\begin{array}{c}F \\
\left(\mathrm{~kg} \cdot \mathrm{m}^{-2} \cdot \mathrm{s}^{-1}\right)\end{array}$ & $a$ & \multicolumn{1}{c}{$b$} \\
\hline 0.100 & 0.429 & 1.18 & 1.37 & 0.83 \\
& & 2.10 & 1.30 & 1.21 \\
\hline 0.150 & 0.200 & 1.15 & 4.58 & 0.03 \\
& & 2.02 & 3.50 & 0.92 \\
0.150 & 0.286 & 1.16 & 3.47 & -0.25 \\
& & 2.05 & 2.73 & 0.58 \\
0.150 & 0.429 & 1.16 & 4.20 & -1.22 \\
& & 2.05 & 2.52 & 0.43 \\
& & 3.01 & 2.66 & 0.26 \\
\hline 0.250 & 0.200 & 1.16 & 4.91 & -0.93 \\
& & 2.04 & 2.57 & 0.94 \\
0.250 & 0.286 & 1.17 & 1.92 & 0.40 \\
& & 2.09 & 1.79 & 0.84 \\
0.250 & 0.429 & 1.16 & 2.31 & -0.16 \\
& & 2.08 & 2.11 & 0.15 \\
\hline 0.375 & 0.429 & 1.16 & 1.88 & 0.05 \\
& & 2.08 & 1.43 & 0.67 \\
\hline
\end{tabular}

直線の勾配は粒子供給量 $F$, 傾斜板間隔 $Y$, 開口比 EなどによりTable 2によって示される。ただしFig.

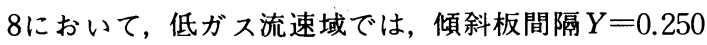
$\mathrm{m}$ よび0.375mの時の直線同士が交わっている。こ れは, 低ガス流速領域ではガスの影響が少ないため, Yをある程度以上に大きくとった場合，その值にかか
わらず，層内を移動する粒子の平均速度はほぼ一定と なるためだと考えられる。したがって, 低ガス流速領 域では $Y$ の值に関係なく, 圧力損失 $\Delta P_{\mathrm{s}} / L$ は同程度の 值を示す。

\section{4. ガス流速分布と粒子軌跡の解析}

気固向流接触装置内の粒子滞留量に影響を与えるの は, ガス供給量のみならず装置内のガス速度分布が重 要であることが分かったが, 粒子の存在下でガス速度 分布を測定することは困難である。そこで，間接的な 検討になるが, 粒子流れを伴わないガス単相流の速度 分布を熱線流速計で測定した。

Figs. 10および11は $Y=0.10 \mathrm{~m}, S=0.10 \mathrm{~m}, E=0.429$ の装置に，ガスを空塔速度 $u=0.74 \mathrm{~m} / \mathrm{s}$ よび $1.25 \mathrm{~m} / \mathrm{s}$ で流した時の時間平均速度分布の実測值である。速度 ベクトルの方向は, 測定部における熱線流速計の值が 最大值を示した時のプローブの角度から求めた。それ ぞれローディング開始直後およびフラッディング開始 直前のガス供給速度に対応している。流れの主流は開 口部を上方に吹き上がり, 次の開口部に向かって蛇行 している。また, 傾斜板の下面および上面に沿って循 環流が認められ, これらはFig. 5の粒子運動状態の写 真観察とも一致している。

気固向流接触装置ではローディング状態で操作する ことが望ましく，ローデイング開始付近での粒子の挙 動を知ることは重要である。この状態では，まだ比較 的粒子濃度が低く，粒子相互間あるいは粒子-流体間 の相互作用を無視し得るとし，実測したガス流速分布 を利用し，単一粒子の運動軌跡を数值解析する。

単一粒子の二次元の運動方程式は次式である。

$$
\begin{aligned}
& \frac{\mathrm{d} v_{\mathrm{x}}}{\mathrm{d} t}=\frac{C_{\mathrm{dx}} A_{\mathrm{p}}}{2 \rho_{\mathrm{p}} V_{\mathrm{p}}}\left|u_{\mathrm{x}}-v_{\mathrm{x}}\right|\left(u_{\mathrm{x}}-v_{\mathrm{x}}\right) \\
& \frac{\mathrm{d} v_{\mathrm{y}}}{\mathrm{d} t}=\frac{C_{\mathrm{dy}} A_{\mathrm{p}}}{2 \rho_{\mathrm{p}} V_{\mathrm{p}}}\left|u_{\mathrm{y}}-v_{\mathrm{y}}\right|\left(u_{\mathrm{y}}-v_{\mathrm{y}}\right)+\left(1-\frac{\rho}{\rho_{\mathrm{p}}}\right) \mathrm{g}
\end{aligned}
$$

粒子-流体間の抗力係数 $C_{\mathrm{d}}$ は, 粒子レイノルズ数 $R e_{\mathrm{p}}$ の 範囲によって次の式を用いて計算した。

$$
\begin{array}{lc}
C_{\mathrm{d}}=24 / R e_{\mathrm{p}}, & R e_{\mathrm{p}}<0.3 \\
C_{\mathrm{d}}=24 / R e_{\mathrm{p}}\left(1+0.15 R e_{\mathrm{p}}^{0.687}\right), & 0.3 \leq R e_{\mathrm{p}} \leq 1000 \\
C_{\mathrm{d}}=0.44 & 1000<R e_{\mathrm{p}} \\
R e_{\mathrm{p}}=\rho d_{\mathrm{p}}\left|u_{\mathrm{x}}-v_{\mathrm{x}}\right| / \mu \text { or } \rho d_{\mathrm{p}}\left|u_{\mathrm{y}}-v_{\mathrm{y}}\right| / \mu
\end{array}
$$

粒子は球形と仮定し，傾斜板および装置壁における粒 子の反発は回転を無視した反発の式5)に従うものとし た。単一粒子の挙動をビデオ撮影し, その画像を解析 


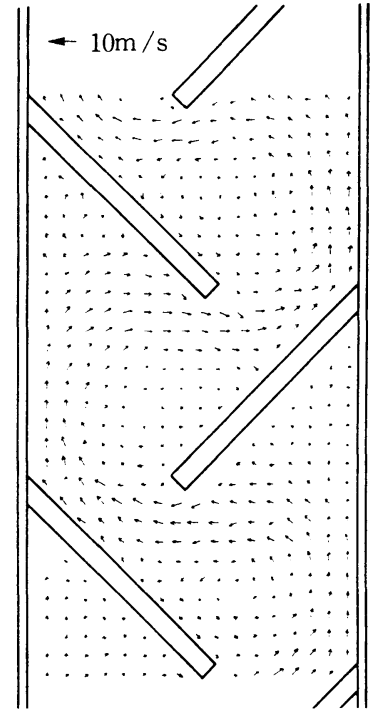

Fig. 10 Distribution of gas velocity without solid particles $(\boldsymbol{u}=0.74 \mathrm{~m} / \mathrm{s})$

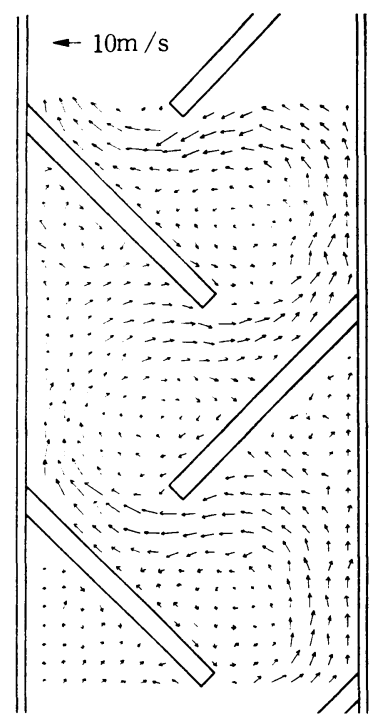

Fig. 11 Distribution of gas velocity without solid particles $(\boldsymbol{u}=1.25 \mathrm{~m} / \mathrm{s})$

し, 粒子の反発係数 $e$ および動摩擦係数 $f_{\mathrm{k}}$ を求めた $\left(e=0.3, f_{\mathrm{k}}=0.09\right)$ 。粒子は, 下から数えて 4 段目の 傾斜板先端から初速度 $v_{\mathrm{x} 0}=-0.05 \mathrm{~m} / \mathrm{s}, v_{\mathrm{y} 0}=0.05$ $\mathrm{m} / \mathrm{s}$ で落下するものとした。Fig. 12は，ガス供給速 度がローデイング点 $(u=0.74 \mathrm{~m} / \mathrm{s})$ のとき，粒子径の 違いによる運動の軌跡を比較したものである。粒径が $250 \mu \mathrm{m}$ の時，粒子はガス流れに沿って傾斜板の背面を

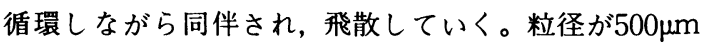
になると，傾斜板背面に形成されている循環流に沿っ
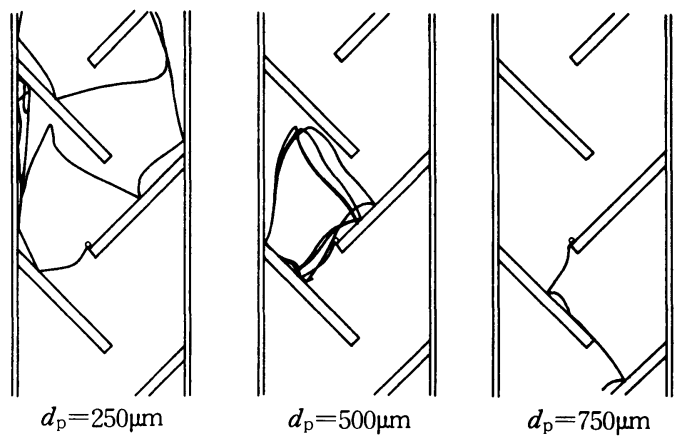

Fig. 12 Trajetories of a single particle in twodimensional flow field $(u=0.74 \mathrm{~m} / \mathrm{s})$

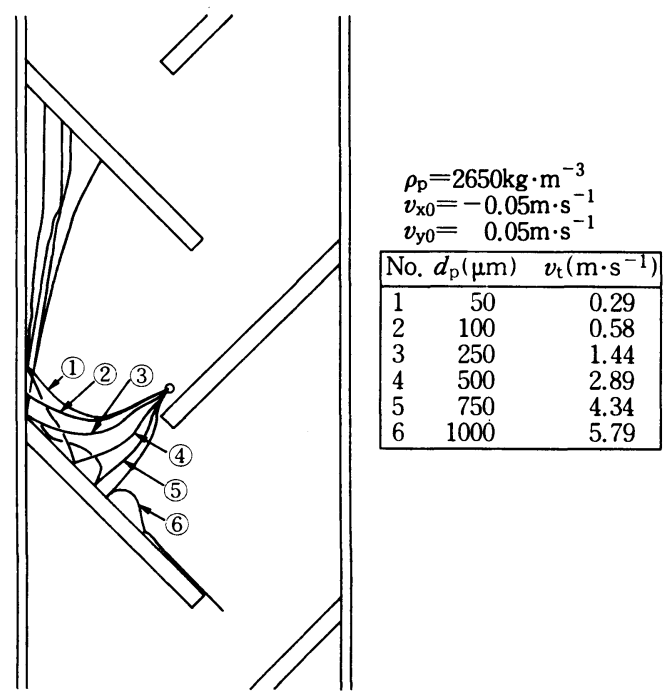

Fig. 13 Trajectories of a single particle in twodimensional flow field $(u=1.25 \mathrm{~m} / \mathrm{s})$

て粒子が循環し，粒子の飛散および降下は見られな い。それ以上の粒径になると，粒子に働く重力が支配 的になり粒子は傾斜板に沿って降下する。Fig. 13は, ガス供給速度がフラッデイング点 $(u=1.25 \mathrm{~m} / \mathrm{s})$ のと きの粒子運動の軌跡を示したものである。重力が支配 的となる粒径が $1000 \mu \mathrm{m}$ 以上の場合を除き，使用した 粒子の大部分が上方に運ばれ，フラッディング状態に あることが示されている。この他, 種々の条件下での 単一粒子運動の解析と, ビデオによる流動状態の観察 結果との比較から, 两者の結果がよく一致することが わかり, 定性的には, 本装置内の粒子の挙動を単一粒 子運動の解析で説明することができた。

\section{5. 結 言}

前報)の，山形鋼を伏せて平行に配列した気固接触 
装置内における循環流の影響をより明らかにするた め,バッフルとして傾斜板を交互に配置した傾斜板内 挿型気固接触装置を試作し，実験およびジグザグ流路 における単一粒子の運動軌跡の数值解析を行い, 以下 に示す知見を得た。

本装置を使用し，粒子滞留量および圧力損失を測定 した結果, 山形鋼の場合と同様に, 粒子のローディン グ開始速度や操作不能となるフラッディング速度が存
在することが明らかとなり，その速度分布を実測した。 ローディング開始速度やフラッディング速度は, 装置 内の傾斜板の開口比を小さくするほど小さな值を示す ことがわかった。また，測定したガス速度分布を用い て, 粒子径の違いによる単一粒子の運動軌跡を解析 し，ビデオによる流動状態の観察結果との比較から, 定 性的には両者の結果がよく一致することがわかった。

\section{Nomenclature}

$A_{\mathrm{p}}$ : cross sectional area of a single particle $\left(\mathrm{m}^{2}\right) \quad u_{\mathrm{fl}}$ : superficial gas velocity at the flooding point

$C_{\mathrm{d}}$ : drag coefficient for a single particle $\quad(-)$

$d_{\mathrm{p}}:$ particle diameter

(m) $\quad u_{\mathrm{ld}}$ : superficial gas velocity at the loading point

$E$ : open spacing fraction $(=1-S / X)$

$(-)$

$\left(\mathrm{m} \cdot \mathrm{s}^{-1}\right)$

$e \quad$ : repulsive factor for a single particle

$(-)$

$u_{\mathrm{mf}}:$ minimum fluidization velocity

$\left(\mathrm{m} \cdot \mathrm{s}^{-1}\right)$

$F \quad$ : feed rate of solid particles $\quad\left(\mathrm{kg} \cdot \mathrm{m}^{-2} \cdot \mathrm{s}^{-1}\right)$

$f_{\mathrm{k}}$ : kinematic friction factor

$(-)$

$f_{\mathrm{p}}$ : volume fraction due to holdup of solid particles

$u_{0} \quad$ : gas velocity at the minimum opening $(=u / E)$

$u_{\mathrm{x}}:$ gas velocity in the $x$-direction

$\left(\mathrm{m} \cdot \mathrm{s}^{-1}\right)$

$g$ : gravitational acceleration

$u_{\mathrm{y}}:$ gas velocity in the $y$-direction

$\left(\mathrm{m} \cdot \mathrm{s}^{-1}\right)$

$L \quad$ : total length of the column

$V_{\mathrm{p}}$ : volume of a single particle

$\left(\mathrm{m} \cdot \mathrm{s}^{-1}\right)$

$\Delta P$ : pressure drop of gas-solid countercurrent flow

$v_{\mathrm{t}} \quad$ : terminal velocity of a single particle

$v_{\mathrm{x}}$ : particle velocity in the $x$-direction $\left(\mathrm{m} \cdot \mathrm{s}^{-1}\right)$

(Pa) $\quad v_{y}:$ particle velocity in the $y$-direction $\left(\mathrm{m} \cdot \mathrm{s}^{-1}\right)$

$\Delta P_{0}$ : pressure drop of gas flow

$(\mathrm{Pa})$

$X \quad$ : width of the column

$(\mathrm{m})$

$\Delta P_{\mathrm{s}}:$ pressure drop due to solid particles $\left(=\Delta P-\Delta P_{0}\right)$

$Y \quad$ : pitch of inclined baffle plates

$(\mathrm{Pa}) \quad \varepsilon \quad$ : void fraction

$R e_{\mathrm{p}}$ : particle Reynolds number

$(-) \quad \rho \quad:$ density of air

$S \quad$ : horizontal length of inclined baffle plates $(\mathrm{m}) \quad \rho_{\mathrm{p}}$ : density of solid particles

$u$ : superficial gas velocity

\section{References}

1) Claus, F. G., F. Verrnes and P. le Goff : Can. J. Chem. Eng., 54, 143(1976)

2) Large, J. F., M. Nand, P. Guinon and M. A. Bergougnou : Chem. Eng. J., 22, 95(1981)

3) Verver, A. B. and W. P. M. van Swaaij : Chem. Eng. J., 45, 119(1986)
4) Nagata, K., M. Nakamura, N. Yamagishi, H. Yamaguchi, H. Mori, S. Toyama, Y. Hamada and S. Tamura : J. Soc. Powder Technol., Japan, 31, 556(1994)

5) Tsuji, Y. : “Kuuki-yusou no Kiso”, p.52, Yo-ken Do(1984) 